\title{
Нормализованный дифференцированный вегетационный индекс охраняемых ландшафтов юга Беларуси
}

\author{
А.П. Гусев ${ }^{1 凶}$, Н.С. Шпилевская ${ }^{1}$ М. Филончик ${ }^{2}$ \\ ${ }^{1}$ Гомельский государственный университет имени Франциска Скорины, Республика Беларусь \\ (246019, г. Гомель, ул. Советская, 104) \\ ${ }^{2}$ Ланьчжоуский транспортный университет, Китай \\ (730070, г. Ланчжоу)
}

\begin{abstract}
Аннотация: Цель. Провести оценку временных трендов усредненных значений NDVI за летний сезон как индикаторов экологического состояния особо охраняемых природных территорий юга Беларуси.

Maтериалы и методы. В статье использовались данные MOD13Q1, которые содержат значения NDVI, рассчитанные по результатам съемки спутника Terra (радиоспектрометр MODIS).

Результаты и обсуждение. На основе продукта MOD13Q1 определены усредненные значения NDVI для летнего сезона в период 2000-2019 гг. для каждой особо охраняемой природной территории (ООПТ). Рассчитаны параметры уравнений линейного тренда NDVI и оценена их статистическая значимость. Установлено, что из 20 изученных ООПТ статистически значимые уравнения тренда и коэффициенты детерминации имеют 10 ООПТ (ландшафтный заказник «Мозырские овраги», национальный парк «Припятский, биологический заказник «Чирковичи» и другие). Точность подбора уравнений тренда характеризуется как средняя $\left(\mathrm{R}^{2}=0,3-0,5\right)$. Для этих ООПТ характерно достоверное увеличение NDVI в 2000-2019 гг. Рассмотрены вероятные причины многолетних трендов значений NDVI в ООПТ юга Беларуси.

Заключение. Положительный тренд усредненных за летний период значений NDVI указывает на увеличение зеленой фитомассы в охраняемых ландшафтах за счет восстановительных сукцессий. Выявлено отсутствие статически достоверных отрицательных трендов значений NDVI в Полесских ООПТ. Это указывает на удовлетворительное состояние охраняемых экосистем.
\end{abstract}

Ключевые слова: особо охраняемые природные территории, дистанционное зондирование, MODIS, NDVI, многолетний тренд, Беларусь.

Для цитирования: Гусев А.П., Шпилевская Н.С., Филончик М. Нормализованный дифференцированный вегетационный индекс охраняемых ландшафтов юга Беларуси // Вестник Воронежского государственного университета. Серия: География. Геоэкология, 2021, № 2, с. 13-19. DOI: https://doi.org/10.17308/geo.2021.2/3442

\section{ВВЕДЕНИЕ}

Важную роль в экологическом балансе региона играют особо охраняемые природные территории (ООПТ) - заповедники, национальные парки, заказники [11]. Каждый из этих объектов представляет собой мозаику лесных, луговых, болотных, водных экосистем, а также антропогенных элементов (автомобильных и железных дорог, населенных пунктов). Состояние природных экосистем на особо охраняемых природных территориях зависит от комплекса факторов, среди которых следует выделить: 1) особенности режима охраны (и его нару- шения местными жителями, браконьерами и т.д.); 2) природные восстановительные процессы - сукцессии растительности, развивающиеся после снижения антропогенного пресса при заповедывании; 3) влияние трансграничных загрязнений; 4) вторжения чужеродных видов растений и животных (в том числе вредителей, возбудителей болезней); 5) влияние региональных климатических изменений.

Эти факторы вызывают как улучшение экологического состояния (восстановление природных экосистем), так и его ухудшение (деградация природных экосистем).

\footnotetext{
(C) Гусев А.П., Шпилевская Н. С., Филончик М., 2021

凹 Гусев Андрей Петрович, e-mail: andi_gusev@mail.ru; t_asha@mail.ru
} 
Для мониторинга экосистем в пределах ООПТ широко используются дистанционные методы [6]. Применение космических методов позволяет осуществлять мониторинг как краткосрочных (пожары, опасные метеоявления), так и многолетних природных и антропогенных процессов (восстановительные сукцессии растительности, деградация под воздействием загрязнения, заболачивание, оврагообразование и т.д.), охватывающие обширные территории [2, 3, 4, 9, 14]. Преимуществом дистанционного зондирования Земли, используемого при мониторинге ООПТ, является высокая степень интегрирования информации во времени и в пространстве, возможность одновременного наблюдения различных компонентов экосистем и пространственной их оценки.

В качестве индикатора состояния ландшафтов может использоваться нормализованный дифференцированный вегетационный индекс - NDVI, имеющий высокую степень корреляции с зеленой фитомассой и продуктивностью экосистем $[12,13,15]$. NDVI рассматривают как индикатор биопродуктивности ландшафтов, поскольку во многих исследованиях в разных регионах мира была установлена высокая степень корреляции между значениями NDVI и первичной продукцией [15].

Целью нашей статьи является оценка временных трендов усредненных значений NDVI за летний сезон как индикаторов экологического состояния особо охраняемых природных территорий юга Беларуси. В ходе исследований решались следующие задачи: определение удельной площади лесных и нелесных экосистем на двух временных срезах - в 2000 и 2018-2019 годах; расчет усредненных значений NDVI для летнего сезона в период 2000-2019 годов для каждой ООПТ; определение параметров уравнений линейного тренда усредненных значений NDVI и оценка их статистической значимости; выяснение вероятных причин многолетних трендов значений NDVI.

\section{МАТЕРИАЛЫ И МЕТОДЫ}

Исследования проводились на юге Беларуси в Белорусском Полесье. Климат - умеренно-континентальный. Средняя температура июля составляет от 18,6 до $20,4^{\circ} \mathrm{C}$, средняя температура января - от минус 5,0 до минус $2,1^{\circ} \mathrm{C}$. Продолжительность периода с температурой выше $10{ }^{\circ} \mathrm{C}$ изменяется от 152 до 168 суток. Годовая сумма температур более $10^{\circ}$ составляет 2400-2700 градусов. Количество осадков в течение года равняется 550-700 мм. Природные экосистемы представлены лесами и болотами. Леса - сосновые, широколиственно-со- сновые, широколиственные, мелколиственные (черноольховые, березовые, осиновые). Болота преимущественно представлены как низинными с черноольховыми, пушистоберезовыми лесами, так и верховыми с сосновыми лесами. Нелесные болота - верховые кустарничково-сфагновые и низинные разнотравно-злаково-осоковые. Почвы - дерново-подзолистые, дерново-глеевые, торфяно-болотные.

Объектами исследований были территории национального парка и 19 заказников, организованные в период с 1969 (национальный парк «Припятский») по 2015 (водно-болотные заказники «Сож», «Старый Жаден», «Морочно») годы. Площадь изучаемых объектов колеблется от 1,4 (биологический заказник «Туровский луг») до 1884,85 (национальный парк «Припятский») км$^{2}$. Величина лесистости колеблется от 0 (биологический заказник «Туровский луг») до 100 (биологические заказники «Чирковичский», «Буда-Кошелевский», «Тырвовичи») процентов.

В статье использовались данные MOD13Q1, содержащие значения NDVI, рассчитанные по результатам съемки спутника Terra (радиоспектрометр MODIS). Эти данные представляют собой растр с пространственным разрешением 250 м, скомпонованный из максимальных значений NDVI за 16 суток. Продукт MOD13Q1 взят c pecypca NASA (https://search.earthdata.nasa.gov/). Для устранения влияния сезонной вариабельности NDVI в процессе анализа использовались композиты только летнего сезона (25.05-09.06, 10.06-25.06, 26.06-11.07, 12.07-27.07, 28.07-12.08, 13.08-28.08). Временной охват - 2000-2019 годы. Для оценки многолетнего тренда рассчитывались усредненные значения NDVI для летнего сезона по 6 композитам за каждый год.

При исследовании исходили из предположения, что тренд NDVI имеет линейный характер и описывается уравнением $y=b * t-\alpha$, параметры которого определяются методом наименьших квадратов. Коэффициент тренда b показывает среднее изменение NDVI при изменении $\mathrm{t}$ (времени) за 1 год. Для оценки точности подбора уравнения тренда использовался коэффициент детерминации $\left(\mathrm{R}^{2}\right)$. Статистическая значимость коэффициента детерминации и уравнения тренда оценивалась с помощью критерия Фишера.

Для изучения структуры растительного покрова ООПТ в 2000 и в 2018-2019 годах использовались данные космической съемки Landsat (Landsat 4-5 TM, Landsat 8 OLI) (время съемки - июнь-ав- 
густ). Критерии отбора снимков: облачность менее $10 \%$, период съемки - июль-август. Данные спутников Landsat взяты с сайта Геологический службы США (https://eartexplorer.usgs.gov/). Для территорий ООПТ проводилось визуальное дешифрирование снимка, на основе которого была создана маска лесных земель. По маске лесных земель рассчитывалась лесистость.

Привязка данных Landsat и MODIS, атмосферная коррекция снимков Landsat, создание маски ООПТ, масок лесного покрова в границах ООПТ на 2 временных срезах, операции зональной статистики выполнены в QGIS 2.14.

\section{РЕЗУЛЬТАТЫ И ОБСУЖДЕНИЕ}

Объекты исследований характеризуются различным режимом и направлением природоохранной деятельности, а также продолжительностью существования в качестве охраняемой природной территории. Нами были изучены изменения усредненных NDVI в национальном парке «Припятский» (комплекс широколиственных, широколиственно-сосновых, сосновых лесов, верховых, переходных и низинных болот), в ландшафтных («Мозырские овраги», «Смычок», «Простырь», «Ольманские болота»), водно-болотных («Старый Жаден», «Сож», «Алес», «Ипуть», «Морочно») и биологических («Лунинский», «Днепро-Сожский», «Буда-Кошелевский», «Бабинец», «Букчанский», «Выдрица», «Октябрьский», «Чирковичский», «Туровский луг») заказниках. Из всех ООПТ национальный парк «Припятский» характеризуется наиболее жестким режимом охраны. В ландшафтных и водно-болотных заказниках, предназначенных для сохранения и восстановления природных и полуприродных ландшафтов, допускается активная рекреационная и туристская деятельность, ограниченная эксплуатация некоторых видов природных ресурсов. В биологических заказниках под охраной находятся только отдельные компоненты животного и растительного мира, вследствие чего, хозяйственная деятельность ограничена, но не запрещена.

Охраняемые экосистемы представлены широколиственными, сосновыми, мелколиственными и смешанными лесами, верховыми, переходными и низинными болотами, лугами и кустарниками, расположенными в пойменных, аллювиальных террасированных, озерно-аллювиальных, озерно-болотных, водно-ледниковых ландшафтах.

По продолжительности существования особо охраняемой природной территории можно выделить следующие группы: 1) образованные более 30 лет назад (национальный парк «Припятский», заказники «Букчанский», «Бабинец», «Чирковичский», «Буда-Кошелевский», «Мозырские овраги»); 2) организованные 10-30 лет назад (заказники «Смычок», «Простырь», «Лунинский»); 3) существующие менее 10 лет (заказники «Старый Жаден», «Алес», «Ипуть», «Морочно», «Сож»).

Анализ показал, что в 2000-2018 годах в разных ООПТ изменения усредненных за летний период значений NDVI были в целом схожи. На территории ландшафтного заказника «Мозырские овраги» (балочно-овражный комплекс с дубравами, грабовыми, березовыми, сосновыми насаждениями) минимальные значения NDVI наблюдались в 2000 году - 0,628 и в 2002 году - 0,604. Максимальные в 2018-2019 годах 0,755-0,759. На территории Национального парка «Припятский» минимальные значения усредненных за летний период NDVI регистрировались в 2000 году - 0,674, а максимальные имели место в 2019 году $-0,815$. В ландшафтном заказнике «Ольманские болота» минимум NDVI приходился на 2000 год $(0,662)$, а максимум - на 2019 году $(0,783)$. В некоторых ООПТ закономерный рост значений NDVI отсутствует. Например, в биологическом заказнике «Туровский луг».

Выполненная оценка трендов усредненных значений NDVI за 2000-2019 годы показала, что из 20 объектов статистически значимые уравнения тренда и коэффициенты детерминации имеют 10 (ландшафтный заказник «Мозырские овраги», национальный парк «Припятский и другие). Точность подбора уравнений тренда характеризуется как средняя $\left(\mathrm{R}^{2}=0,3-0,5\right)$. Наибольшее значение коэффициента детерминации характерно для Национального парка «Припятский» $\left(\mathrm{R}^{2}=0,47\right.$, т.е. в $47 \%$ случаев изменение $\mathrm{t}$ влияет на NDVI). Относительно высокие значения коэффициента детерминации также установлены для биологического заказника «Тырвовичи» $\left(\mathrm{R}^{2}=0,42\right)$, ландшафтного заказника «Мозырские овраги» $\left(\mathrm{R}^{2}=0,34\right)$, заказник республиканского значения «Выдрица» $\left(\mathrm{R}^{2}=0,34\right)$, биологический заказник «Лунинский» $\left(\mathrm{R}^{2}=0,34\right)$. Коэффициенты детерминации и уравнения тренда статистически не достоверны для таких ООПТ, как биологический заказник «Туровский луг», водно-болотные заказники «Алес», «Ипуть», «Сож», ландшафтный заказник «Простырь». Таким образом, зависимости достоверного тренда NDVI от типа ООПТ не наблюдается.

Причины изменения NDVI в пределах рассматриваемых ООПТ могут быть различными. 
Так, для бывших сельскохозяйственных и лесохозяйственных земель, оказавшихся в пределах ООПТ, характерно развитие восстановительных сукцессий растительности, которые за 20 лет привели к увеличению фитомассы как за счет роста лесистости территории, так в связи с увеличением возраста древостоев. Увеличение фитомассы, соответственно, отражается в постепенном росте средних значений NDVI.

Однако, достоверной статистической связи между изменением лесистости и характером тренда NDVI не установлено. Были рассчитаны изменения лесистости территории изучаемых объектов за 20 лет (разница между 2000 и 2018-2019 гг.). Для 16 ООПТ характерно увеличение лесистости, для 1 ООПТ - снижение. В 3 ООПТ лесистость не изменилась. ООПТ, имеющие статистически достоверный положительный тренд значений NDVI, характеризуются колебаниями прироста лесистости за 20 лет: от 0 («Лунинский», «Тырвовичи») до 16,0 \% («Чирковичский», «Октябрьский»). Охраняемые природные территории, для которых статистически достоверный тренд не установлен, характеризуются колебаниями прироста лесистости: от -18,4 («Выдрица») до 12,5 \% («Смычок»).

Продолжительность режима охраны, вероятно, является одним из факторов, благоприятствующих росту зеленой фитомассы и соответственно увеличению усредненных значений NDVI. Так, из 6 ООПТ, существующих более 30 лет, 5 (83,3 \%) характеризуются наличием статистически достоверного положительного тренда NDVI. При этом, для всех 5 ООПТ, образованных менее 10 лет назад, статистически достоверного тренда NDVI не обнаружено.

Еще одним важным фактором, влияющим на изменения усредненных значений NDVI, является соотношение площадей лесных и нелесных экосистем. В биологических заказниках, организованных в 90-е годы и характеризующихся высокой удельной площадью лесных экосистем (70-100 \%), также наблюдается достоверное увеличение NDVI, которое может объясняться ростом возраста древостоев. К таким ООПТ относятся биологические заказники «Бабинец», «Чирковичи», «Октябрьский», «Тырновичи», «Лунинский».

На территории Национального парка «Припятский» и ландшафтного заказника «Ольманские болота» лесные и болотные экосистемы представлены примерно в равной мере. При этом за 2000-2019 годы лесистость на этих охраняемых природных территориях практически не измени- лась (рост в пределах 0,5-2 \%). Положительный тренд NDVI, вероятно, обусловлен увеличением фитомассы как лесной, так и соответственно болотной растительности.

Для большинства водно-болотных заказников («Сож», «Ипуть», «Алес», «Морочно»), некоторых ландшафтных («Выдрица», «Простырь», «Смычок») и биологических («Туровский луг», «Днепро-Сожский», «Буда-Кошелевский», «Букчанский») заказников достоверного роста NDVI не наблюдается. Почти все эти объекты (кроме заказников «Буда-Кошелевский» и «Букчанский») приурочены к пойменным ландшафтам и характеризуются относительно высокой удельной площадью луговых экосистем (от 30 до 100 \%).

Вероятно, одной из причин положительных трендов усредненных значений NDVI за летний сезон может являться потепление климата. Так, в Белорусском Полесье за последние 20-25 лет по сравнению с периодом 1881-1990 годов средние температуры, июля и августа увеличились на $1,3-1,4{ }^{\circ} \mathrm{C}$. Годовая сумма активных температур (выше $10{ }^{\circ} \mathrm{C}$ ) в 2006-2013 годах практически на всей территории региона превысила 2600 градусов, что обусловило на юге Беларуси выделение новой агроклиматической зоны [7]. Можно предположить, что влияние потепления климата на зеленую фитомассу в лесных, болотных и луговых экосистемах Белорусского Полесья проявляется по-разному, вызывая как рост этого показателя в одних случаях, так и его снижение в других. Неоднозначное влияние потепления климата на изменения NDVI показано в исследованиях, проводимых в разных регионах мира $[5,8,10]$.

Следует отметить, что для значительной части территории региона был установлен достоверный рост значений NDVI (выполнено сравнение средних значений NDVI в летний период на двух временных отрезках - 2000-2004 и 2014-2018 гг.), предположительно обусловленный изменениями биопродуктивности ландшафтов под влиянием сложного сочетания климатических изменений и хозяйственной деятельности $[1,2]$.

\section{ЗАКЛЮЧЕНИЕ}

В ходе исследований установлено, что в 10 из 20 изученных ООПТ отмечается положительный многолетний тренд усредненных за летний период значений NDVI (национальный парк «Припятский», ландшафтные заказники «Ольманские болота» и «Мозырские овраги», биологические заказники «Чирковичи», «Октябрьский»). Эти ООПТ характеризуются значительной удельной 
площадью лесных экосистем и относительно продолжительным временем с момента образования.

Для другой половины изученных ООПТ статистически достоверного тренда не выявлено. К этой группе относятся водно-болотные, ландшафтные и биологические заказники, приуроченные к пойменным ландшафтам и отличающиеся относительно высокой удельной площадью луговых экосистем (от 30 до 100 \%), а также малой продолжительностью природоохранного режима (5 ООПТ организованы менее 10 лет назад).

Предполагается, что положительный тренд усредненных за летний период значений NDVI указывает на увеличение зеленой фитомассы в охраняемых ландшафтах за счет восстановительных сукцессий, ведущих к росту возраста древостоя в лесных и лесоболотных экосистемах, а также, вероятно, за счет увеличения продуктивности лесов в связи с потеплением климата.

Отсутствие статически достоверных отрицательных трендов значений NDVI в полесских ООПТ указывает на удовлетворительное состояние охраняемых экосистем и на отсутствие (или незначительный пространственный масштаб) каких-либо негативных процессов, вызывающих деградацию растительного покрова.

\section{СПИСОК ЛИТЕРАТУРЫ}

1. Гусев А.П. Дистанционные индикаторы ландшафтно-экологических тенденций (на примере юго-востока Беларуси) // Ученые записки Крымского федерального университета имени В.И. Вернадского. География. Геология, 2019, т. 5 (71), № 3, с. 127-135.

2. Гусев А.П. Изменения NDVI как индикатор динамики экологического состояния ландшафтов (на примере восточной части Полесской провинции // Вестник Воронежского государтвенного университета. Серия: География. Геоэкология, 2020, № 1, c. 101-107. DOI: 10.17308/geo.2020.1/2667.

3. Елсаков В. В., Кулюгина Е.Е. Растительный покров Югорского полуострова в условиях климатических изменений последних десятилетий // Исследование Земли из космоса, 2014, № 3, с. 65-77.

4. Крутских Н. В., Кравченко И. Ю. Использование космоснимков Landsat для геоэкологического мониторинга урбанизированных территорий // Современные проблемы дистанционного зондирования Земли из космоса, 2018, т. 15, № 2, с. 159-168.

5. Курганович К.А., Голятина М.А. Пространственно-временной отклик NDVI на изменение климатических характеристик в Забайкальском крае за период 2000-2014 гг. // Вестник Забайкальского государственного университета, 2015, № 9, с. 10-20.
6. Лабутина И.А., Балдина Е.А. Использование данных дистанционного зондирования для мониторинга экосистем ООПТ. М.: WWF России, 2011. 88 c.

7. Логинов В.Ф. Климатические условия Беларуси за период инструментальных наблюдений // Наука и инновации, 2016, № 9, с. 25-29.

8. Тельнова Н. О. Выявление и картографирование многолетних трендов NDVI для оценки вклада изменений климата в динамику биологической продуктивности агроэкосистем лесостепной и степной зон Северной Евразии // Современные проблемь дистанционного зондирования Земли из космоса, 2017, т. 14, № 6, c. $97-107$.

9. Терехин Э.А., Чендев Ю.Г. Оценка изменения лесистости в современный период на юге Среднерусской возвышенности с использованием материалов разновременных космических съемок // Современные проблемы дистанционного зондирования Земли из космоса, 2018, т. 15. № 3, с. 114-126.

10. Титкова Т.Б., Виноградова В.В. Изменение климата в переходных природных зонах севера России и их проявление в спектральных характеристиках ландшафтов // Современные проблемы дистанционного зондирования Земли из космоса, 2019, т. 16, № 5, c. $310-323$

11. Штильмарк Ф.Р. Заповедное дело России: теория, практика, история. М.: Товарищество научных изданий «КМК», 2014. 511 с.

12. Box E.O., Holben B.N., Kalb V. Accuracy of the AVHRR Vegetation Index as a predictor of biomass, primary productivity and net $\mathrm{CO}_{2}$ flux // Vegetatio, 1989, vol. 80 , pp. 71-89.

13. Phillips L.B., Hansen A.J., Flather C.H. Evaluating the species energy relationship with the newest measures of ecosystem energy: NDVI versus MODIS primary production // Remote Sensing of Environment, 2008, vol. 112, pp. 4381-4392.

14. Yang J., Weisberg P.J., Bristow N.A. Landsat remote sensing approaches for monitoring long-term tree cover dynamics in semi-arid woodlands: Comparison of vegetation indices and spectral mixture analysis // Remote Sensing of Environment, 2012, vol. 119, pp. 62-71.

15. Yengoh G.T. et al. The use of the Normalized Difference Vegetation Index (NDVI) to assess land degradation at multiple scales: a review of the current status, future trends, and practical considerations. Lund University Centre for Sustainability Studies: LUCSUS, 2014. 80 p.

Конфликт интересов: Авторы декларируют отсутствие явных и потенциальных конфликтов интересов, связанных с публикацией настоящей статьи.

Поступила в редакциюю 30.07.2020 Принята к публикации 28.05.2021 


\title{
Normalized Difference Vegetation Index in Specially Protected Natural Areas of Southern Belarus
}

\author{
A.P. Gusev ${ }^{1} \stackrel{\square}{ }$, N.S. Shpilevskaya ${ }^{1}$, M. Filonchik ${ }^{2}$ \\ ${ }^{1}$ FranciskSkorinaGomelStateUniversity, Belarus \\ (104, Sovetskaya St., Gomel, 246019) \\ ${ }^{2}$ Lanzhou Jiaotong University, China \\ (Lanzhou, 730070)
}

\begin{abstract}
Purpose. Assessment of time trends of the averaged NDVI values for the summer season as indicators of the ecological state of specially protected natural areas in the south of Belarus.

Methods. The article used MOD13Q1 data, which contains the NDVI values calculated from the results of the Terra satellite imagery (MODIS radio spectrometer).

Results. Based on the MOD13Q1 product, the average NDVI values for the summer season in the period 2000-2019 for each specially protected natural area (SPNA) were determined. The parameters of the NDVI linear trend equations are calculated and their statistical significance is estimated. It has been established that out of 20 SPNA studied, statistically significant trend equations and determination coefficients have 10 SPNA (the Mozyr Ravines landscape reserve, the Pripyatsky National Park, the Chirkovichi Biological Reserve and others). The accuracy of the selection of trend equations is characterized as average $(\mathrm{R} 2=0,3-0,5)$. These protected areas are characterized by a significant increase in NDVI in 2000-2019. Probable causes of long-term trends in NDVI values in protected areas of southern Belarus are considered.

Conclusion. A positive trend of NDVI values averaged over the summer period indicates an increase in green phytomass in protected landscapes due to restoration successions. The absence of statistically significant negative trends in NDVI values in Polesie protected areas was revealed. This indicates a satisfactory state of protected ecosystems.
\end{abstract}

Key words: specially protected natural areas, remote sensing, MODIS, NDVI, long-termtrend, Belarus.

For citation: Gusev A.P., Shpilevskaya N.S., Filonchik M. Normalized Difference Vegetation Index in Specially Protected Natural Areas of Southern Belarus. Vestnik Voronezskogo gosudarstvennogo universiteta. Seria: Geografia. Geoekologia, 2021, no. 2, pp. 13-19. (In Russ.). DOI: https://doi.org/10.17308/geo.2021.2/3442

\section{REFERENCES}

1. Gusev A.P. Distantsionnye indikatory landshaftno-ekologicheskikh tendentsii (na primere yugo-vostoka Belarusi) [Remote indicators of landscape and ecological trends (on the example of the south-east of Belarus)]. Uchenye zapiski Krymskogo federal'nogo universiteta imeni V.I. Vernadskogo. Geografiya. Geologiya, 2019, vol. 5, no. 3, pp. 127-135. (In Russ.)

2. Gusev A.P. Izmeneniya NDVI kak indikator dinamiki ekologicheskogo sostoyaniya landshaftov (na primere vostochnoi chasti Polesskoi provintsii) [Changes in the NDVI as an indicator of the dynamics of the ecological state of landscapes (on the example of the eastern part of the Polesie province]. Vestnik Voronezhskogo gosu- dartvennogo universiteta. Seria: Geografia. Geoekologia, 2020, no. 1, pp. 101-107. DOI: 10.17308/geo.2020.1/2667 (In Russ.)

3. Elsakov V.V., Kulyugina E.E. Rastitel'nyi pokrov Yugorskogo poluostrova $\mathrm{v}$ usloviyakh klimaticheskikh izmenenii poslednikh desyatiletii [Vegetation cover of the Yugorsky Peninsula in the context of climatic changes in recent decades]. Issledovanie Zemli iz kosmosa, 2014, no. 3, pp. 65-77. (In Russ.)

4. Krutskikh N.V., Kravchenko I.Yu. Ispol'zovanie kosmosnimkov Landsat dlya geoekologicheskogo monitoringa urbanizirovannykh territorii [The use of Landsat satellite images for geoecological monitoring of urbanized areas]. Sovremennye problemy distantsionnogo zondi-

(C) Gusev A.P., Shpilevskaya N. S., Filonchik M., 2021

$\triangle$ Andrei P. Gusev, e-mail: andi_gusev@mail.ru; t_asha@mail.ru

The content is available under Creative Commons Attribution 4.0 License. 
rovaniya Zemli iz kosmosa, 2018, vol. 15, no. 2, pp. 159168. (In Russ.)

5. Kurganovich K.A., Golyatina M.A. Prostranstvenno-vremennoi otklik NDVI na izmenenie klimaticheskikh kharakteristik v Zabaikal'skom krae za period 2000-2014 gg. [Spatio-temporal response of NDVI to changes in climatic characteristics in the Trans-Baikal Territory for the period 2000-2014]. Vestnik Zabaikal'skogo gosudarstvennogo universiteta, 2015, no. 9, pp. 10-20. (In Russ.)

6. Labutina I.A., Baldina E.A. Ispol'zovanie danny$k h$ distantsionnogo zondirovaniya dlya monitoringa ekosistem OOPT [Using remote sensing data to monitor PA ecosystems]. Moscow: WWF Rossii, 2011. 88 p. (In Russ.)

7. Loginov V.F. Klimaticheskie usloviya Belarusi za period instrumental'nykh nablyudenii [Climatic conditions of Belarus for the period of instrumental observations]. Nauka i innovatsii, 2016, no. 9, pp. 25-29. (In Russ.)

8. Tel'nova N.O. Vyyavlenie i kartografirovanie mnogoletnikh trendov NDVI dlya otsenki vklada izmenenii klimata $\mathrm{v}$ dinamiku biologicheskoi produktivnosti agroekosistem lesostepnoi i stepnoi zon Severnoi Evrazii [Identification and mapping of long-term NDVI trends to assess the contribution of climate change to the dynamics of biological productivity of agroecosystems in the forest-steppe and steppe zones of Northern Eurasia]. Sovremennye problemy distantsionnogo zondirovaniya Zemli iz kosmosa, 2017, vol. 14, no. 6, pp. 97-107. (In Russ.)

9. Terekhin E.A., Chendev Yu. G. Otsenka izmeneniya lesistosti v sovremennyi period na yuge Srednerusskoi vozvyshennosti $\mathrm{s}$ ispol'zovaniem materialov raznovremennykh kosmicheskikh s"emok [Assessment of changes in forest cover in the modern period in the south of the Central Russian Upland using materials from space surveys of different times]. Sovremennye problemy distantsionnogo zondirovaniya Zemli iz kosmosa, 2018, vol. 15, no. 3, pp. 114-126. (In Russ.)

\section{Гусев Андрей Петрович}

кандидат геолого-минералогических наук, декан геолого-географического факультета Гомельского государственного университета им. Ф. Скорины, г. Гомель, Республика Беларусь, ORCID: 0000-0002-1169-1172, e-mail: andi_gusev@mail.ru

Шпилевская Наталья Станиславовна

старший преподаватель Гомельского государственного университета им. Ф. Скорины, г. Гомель, Республика Беларусь, e-mail: t_asha@mail.ru

Филончик Николай Николаевич

доктор технических наук, преподаватель Ланьчжоуского транспортного университета, г. Ланьчжоу, Китай, e-mail: filonchyk.mikalai@gmail.com
10. Titkova T. B., Vinogradova V. V. Izmenenie klimata v perekhodnykh prirodnykh zonakh severa Rossii i ikh proyavlenie v spektral'nykh kharakteristikakh landshaftov [Climate change in transitional natural zones of the north of Russia and their manifestation in the spectral characteristics of landscapes]. Sovremennye problemy distantsionnogo zondirovaniya Zemli iz kosmosa, 2019, vol. 16, no. 5, pp. 310-323. (In Russ.)

11. Shtil'mark F. R. Zapovednoe delo Rossii: teori$y a$, praktika, istoriya [Conservation management in Russia: theory, practice, history]. Moscow: Tovarishchestvo nauchnykh izdanii "KMK”, 2014. 511 p. (In Russ.)

12. Box E.O., Holben B.N., Kalb V. Accuracy of the AVHRR Vegetation Index as a predictor of biomass, primary productivity and net $\mathrm{CO}_{2}$ flux. Vegetatio, 1989, v. 80, pp. 71-89.

13. Phillips L. B., Hansen A. J., Flather C.H. Evaluating the species energy relationship with the newest measures of ecosystem energy: NDVI versus MODIS primary production. Remote Sensing of Environment, 2008, v. 112, pp. 4381-4392.

14. Yang J., Weisberg P. J., Bristow N.A. Landsat remote sensing approaches for monitoring long-term tree cover dynamics in semi-arid woodlands: Comparison of vegetation indices and spectral mixture analysis. Remote Sensing of Environment, 2012, v. 119, pp. 62-71.

15. Yengoh G. T. et al. The use of the Normalized Difference Vegetation Index (NDVI) to assess land degradation at multiple scales: a review of the current status, future trends, and practical considerations. Lund University Centre for Sustainability Studies: LUCSUS, 2014. 80 p.

Conflict of interest: The authors declare no information of obvious and potential conflicts of interest related to the publication of this article.

Received: 30.07 .2020

Accepted: 28.05.2021

Andrei P. Gusev

Cand. Sci. (Geol.-Miner.), Dean of the Faculty of Geology and Geography, Francisk Skorina Gomel State University, Gomel, Belarus, ORCID: 0000-0002-11691172, e-mail: andi_gusev@mail.ru

Natalia S. Shpilevskaya

Senior Lecturer of the Department of Ecology, Francisk Skorina Gomel State University, Gomel, Belarus, e-mail: t_asha@mail.ru

Mikalai Filonchyk

Doc. Sci. (Engineer.), Lecturer of the Faculty of Geomatics, Lanzhou Jiaotong University, Lanzhou, China, e-mail: filonchyk.mikalai@gmail.com 